\title{
Prevalence and Risk Factors for Positive Nasal Methicillin-Resistant Staphylococcus aureus Carriage among Orthopedic Patients in Korea
}

\author{
Sung-Woo Choi ${ }^{1,+, *}$, Jae Chul Lee ${ }^{1}{ }^{\circledR}$, Jahyung Kim ${ }^{1}$, Ji Eun Kim ${ }^{2}$, Min Jung Baek ${ }^{3,+}$, \\ Se Yoon Park ${ }^{4}$, Suyeon Park ${ }^{5}$ and Byung-Joon Shin ${ }^{1, *}$ \\ 1 Department of Orthopedic Surgery, Soonchunhyang University Hospital, College of Medicine, \\ Seoul 04401, Korea; jlee@schmc.ac.kr (J.C.L.); t0152@schmc.ac.kr (J.K.) \\ 2 Department of Laboratory Medicine, Soonchunhyang University College of Medicine, Seoul 04401, Korea; \\ jkim@schmc.ac.kr \\ 3 Department of Obstetrics and Gynecology, Bundang CHA Hospital, Seongnam 13496, Korea; \\ goodgood75@naver.com \\ 4 Division of Infectious Diseases, Department of Internal Medicine, Soonchunhyang University Hospital, \\ College of Medicine, Seoul 04401, Korea; sypark@schmc.ac.kr \\ 5 Department of Biostatistics, Soonchunhyang University College of Medicine, Seoul 04401, Korea; \\ sue3517@schmc.ac.kr \\ * Correspondence: swchoi@schmc.ac.kr (S.-W.C.); schsbj@schmc.ac.kr (B.-J.S.); Tel.: +82-2-709-9259 (S.-W.C.); \\ +82-2-709-9250 (B.-J.S.) \\ + These authors contributed equally to this paper.
}

Received: 14 April 2019; Accepted: 7 May 2019; Published: 8 May 2019

\begin{abstract}
Methicillin-resistant Staphylococcus aureus (MRSA) causes purulent skin and soft tissue infections as well as other life-threatening diseases. Recent guidelines recommend screening for MRSA at the time of admission. However, few studies have been conducted to determine the prevalence and risk factors for MRSA colonization. A prospective data collection and retrospective analysis was performed. MRSA screening tests were performed using nasal swabs in patients enrolled between January 2017 and July 2018. Demographic data, socio-economic data, medical comorbidities, and other risk factors for MRSA carriage were evaluated among 1577 patients enrolled in the study. The prevalence of MRSA nasal carriage was $7.2 \%$. Univariate regression analysis showed that colonization with MRSA at the time of hospital admission was significantly related to patient age, body mass index, smoking, alcohol, trauma, recent antibiotic use, and route of hospital admission. Multiple logistic regression analysis for the risk factors for positive MRSA nasal carriage showed that being under- or overweight, trauma diagnosis, antibiotic use one month prior to admission, and admission through an emergency department were related to MRSA colonization. This study highlights the importance of a preoperative screening test for patients scheduled to undergo surgery involving implant insertion, particularly those at risk for MRSA.
\end{abstract}

Keywords: Methicillin-resistant Staphylococcus aureus (MRSA); nasal screening test; infection; prevalence; risk factors

\section{Introduction}

The emergence of methicillin-resistant Staphylococcus aureus (MRSA) since the early 1960s and its spread throughout hospitals and communities decades later have complicated antibiotic therapy [1-5]. The rate of methicillin resistance is higher in the orthopedics department, where artificial implantation is more common than in other medical specialties [6]. If the infection is caused by MRSA, either due to 
antibiotic resistance or biofilm formation, the treatment of an orthopedic infection becomes difficult and may lead to a higher economic burden [7]. Therefore, early detection and prevention of MRSA are important, particularly among orthopedic patients.

The recent guidelines published by the Society for Health Care Epidemiology for America recommend surveillance of cultures at the time of hospital admission for patients scheduled to undergo high-risk surgeries, including some orthopedic and cardiothoracic procedures [8,9]. The Korea Center for Disease Control and Prevention suggests a screening test only for patients who are admitted to high-risk departments such as the intensive care unit, the hemato-oncology department, and the organ transplantation department; patients with a prior diagnosis of MRSA; and patients transferred from a nursing facility [10]. The recommended screening method for MRSA is nasal sampling because the anterior nasal cavity is one of the preferred carrier sites of this bacterium and because the frequency of skin colonization depends on nasal carriage [11,12]. In addition, Yano et al. [13] reported that patients with positive preoperative nasal cultures for MRSA had a higher occurrence of surgical site infection with MRSA after orthopedic surgery.

However, a limited number of studies have been conducted to determine the prevalence and risk factors for colonization at the time of admission in orthopedic patients [14-18], especially in Korea. The prevalence of MRSA is extremely high in Korea. The Asian Network for Surveillance of Resistant Pathogens (ANSORP) study, which included seven hospitals in Korea, showed an average MRSA prevalence of $77.6 \%$ for nosocomial S. aureus isolates [19]. The recent report of the Regional Resistance Surveillance (RRS) program showed that $73 \%$ of the clinical S. aureus isolates from two hospitals in Korea were MRSA [20]. Korea has the highest MRSA prevalence among the 12 surveillance countries in the RRS program [20,21].

The present study primarily aimed to assess the prevalence of MRSA carriage in the orthopedic department. The secondary objective was to identify potential risk factors for MRSA colonization with respect to the demographic and medical data.

\section{Material and Methods}

The study involved prospective data collection and retrospective data analysis and was conducted between January 2017 and July 2018 at the orthopedic surgery department of Soonchunhyang University Hospital and approved by the Institutional Review Board (IRB No.: SCHUH 2018-11-021).

\subsection{Inclusion and Exclusion Criteria}

The patients admitted to the orthopedic surgery department of Soonchunhyang University Hospital, Korea were enrolled in the study based on the following inclusion criteria: patients aged 18 to 90 years were included in the study and patients with a current infection were excluded.

\subsection{Sampling}

The patients, who were admitted to the hospital during the study period and satisfied the inclusion criteria, had nasal swabs collected from them. All sampling was performed by well-trained orthopedic nurses. Nasal swabs were obtained within a day of admission. A sterile transport swab (COPAN, Brescia, Italy) was rotated in the anterior nasal cavity of the patients by the nurses. The swab was transported at room temperature and each swab was processed as described here within four hours of collection. Direct culture was performed onto chromID MRSA agar (bioMérieux, Nürtingen, Germany) and was examined at 24 and 48 hours after incubation. A positive culture was defined as growth with morphological features comparable to MRSA. This was confirmed by the coagulase test using a commercial latex agglutination kit (Pastorex Staph Plus, Bio Rad Laboratories, Hemel Hempstead, UK).

\subsection{Data Collection}

Data collection was coordinated by an orthopedic surgeon who completed standardized forms for each included patient. Overall data was recorded for the following variables: demographic 
characteristics, socio-economic characteristics, medical comorbidities, and other risk factors for MRSA carriage. Sex, age, body mass index (BMI), history of smoking and alcohol consumption, diagnosis of trauma or disease, and body part involved were analyzed as demographic data. BMI was divided into four groups (underweight $\left(<18.5 \mathrm{~kg} / \mathrm{m}^{2}\right)$, normal weight $\left(18.5-25 \mathrm{~kg} / \mathrm{m}^{2}\right)$, overweight $\left(25-30 \mathrm{~kg} / \mathrm{m}^{2}\right)$, and obese $\left(>30 \mathrm{~kg} / \mathrm{m}^{2}\right)$ ) [22]. Smoking history was classified into three groups (never-smoker, ex-smoker, and current-smoker). An ex-smoker was defined as someone who had smoked more than 100 cigarettes in their lifetime but had not smoked in the last 28 days [23]. A current-smoker was defined as an adult who had smoked more than 100 cigarettes in his or her lifetime and was still smoking. History of alcohol consumption was divided into three groups (never-drinker, former-drinker, and current-drinker). A current-drinker was a person who consumed up to 12 drinks per year, while a former-drinker was a patient who had stopped drinking for $>1$ year [24]. The body part involved was divided into five categories (spine, knee and shoulder, hand and elbow, hip, and foot). Using the ICD-10-CM (International Classification of Diseases, Tenth Revision, Clinical Modification) codes, patients were divided into two groups (coded as trauma (S) and disease (M)). Education status was collected as socio-economic data [25-27]. Medical comorbidities included hypertension, diabetes mellitus, cardiovascular diseases, hepatic diseases, and dialysis. Other risk factors for MRSA carriage were recent hospitalization, recent antibiotics use, presence of a ureteral catheter, and type of hospital admission (i.e., whether emergency or outpatient department) (Table 1). Recent hospitalization and recent antibiotic use were defined as stationary hospitalization within 12 months prior to admission and antimicrobial therapy within one month before the screening test, respectively [28].

Table 1. Overview of collected patient data.

\begin{tabular}{|c|c|}
\hline Patient Data & Type of Acquired Information \\
\hline \multirow[t]{5}{*}{ Demographic } & Gender \\
\hline & Age \\
\hline & Body mass index (BMI) \\
\hline & Smoking (current-smoker/ex-smoker/never-smoker) \\
\hline & Regular consumption of alcohol (current-drinker/former-drinker/never-drinker) \\
\hline Socio-economic & $\begin{array}{c}\text { Status of education (under high school/high school graduate/denied or } \\
\text { unanswered) }\end{array}$ \\
\hline Medical comorbidities & Hypertension, diabetes mellitus, cardiovascular diseases, hepatic disease, dialysis \\
\hline \multirow[t]{6}{*}{ Other risk factors } & Stationary hospitalization in last 12 months \\
\hline & Antimicrobial therapy in the past month \\
\hline & Presence of urethral catheter \\
\hline & Route of admission (ER/OPD) \\
\hline & Trauma/disease \\
\hline & Body parts involved (spine/knee and shoulder/hand and elbow/hip/foot) \\
\hline
\end{tabular}

\subsection{Statistical Analysis}

Statistical analysis was performed using parametric or nonparametric tests, where appropriate. Logistic regression analysis was used to identify independent predictors of colonization with MRSA at the time of admission to the hospital as well as clinical conditions associated with the development of symptomatic MRSA infection. The association between the risk factors and MRSA colonization was analyzed using the chi-square test or Fisher's exact test, as appropriate. Data were analyzed using SPSS Statistics (Statistical Package for the Social Sciences, version 25.0; 2017, IBM Corp. Armonk, NY, USA) and two-tailed $p$-values of $\leq 0.05$ were considered as statistically significant. 


\section{Results}

\subsection{Overall Result}

A total of 1577 patients were enrolled during the study period. Of these, 617 (39.1\%) were women and $960(60.9 \%)$ were men. The average patient age was 59.2 years; particularly, 288 patients $(18.3 \%)$ were aged under 40 years, 776 (49.2\%) were aged between 40 and 70 years, and 513 (32.5\%) were aged older than 70 years. A total of 1332 patients $(84.5 \%)$ were tested in the ward after admission, while $245(15.5 \%)$ were tested in the outpatient department. Ultimately, 114 patients were found to be colonized with MRSA; thus, the prevalence of nasal MRSA carriage was $7.2 \%$. Of the 114 colonized samples, 99 (86.8\%) samples were collected after admission and $15(13.2 \%)$ samples were collected in the outpatient department.

\subsection{Risk Factors}

\subsubsection{Univariate Logistic Regression Analysis}

Selected variables of interest were subjected to analysis (Tables 2 and 3). The results of the univariate logistic regression analysis showed that the colonization with MRSA at the time of hospital admission was significantly related to patient age, BMI, smoking, alcohol consumption, body part involved, diagnosis of trauma, type of hospital admission, and recent antibiotic use (Table 4). Patients aged 40 to 70 years and those older than 70 years had 0.237 (95\% Confidence Interval (CI): 0.151-0.374; $p<0.001)$ and 0.292 (95\% CI: $0.180-0.474 ; p<0.001)$ times the risk of being a carrier of MRSA as compared to those aged under 40 years, respectively. Additionally, patients whose BMI was under $18.5 \mathrm{~kg} / \mathrm{m}^{2}, 25$ to $30 \mathrm{~kg} / \mathrm{m}^{2}$, and higher than $30 \mathrm{~kg} / \mathrm{m}^{2}$ had 3.432 (95\% CI: 1.308-9.000; $p=0.012$ ), 0.290 (95\% CI: 0.153-0.550; $p<0.01$ ), 0.637 (95\% CI: 0.238-1.702; $p=0.369$ ) times the risk of being an MRSA carrier than those with a normal BMI. Current-smokers had an odds ratio of 4.204 (95\% CI: 2.801-6.309; $p<0.01$ ) and current-drinkers had an odds ratio of 4.204 (95\% CI: 3.250-7.223; $p<0.001$ ). Patients diagnosed with trauma had 3.401 (95\% CI: 1.593-7.261; $p<0.01)$ times the risk of being an MRSA carrier than those diagnosed with disease. Furthermore, those who were recently treated with antibiotics tended to have an increased chance of being an MRSA carrier, with an odds ratio of 4.199 (95\% CI: 2.831-6.228; $p<0.01$ ). Lastly, patients admitted through the emergency department had 6.915 (95\% CI: 2.863-16.702; $p<0.01$ ) times the risk of being an MRSA carrier than those admitted through the outpatient department. Meanwhile, there was no strong association between MRSA carriage and other medical comorbidities, recent hospitalization, the presence of a urinary catheter, and socio-economic background.

Table 2. Descriptive logistic regression analysis from data obtained at admission (demographics, socio-economic status).

\begin{tabular}{|c|c|c|c|c|}
\hline & $\begin{array}{c}\text { Number of } \\
\text { Patients }\end{array}$ & $\begin{array}{c}\text { MRSA (-) } \\
\text { (1463 Patients) }\end{array}$ & $\begin{array}{c}\text { MRSA (+) } \\
\text { (114 Patients) }\end{array}$ & \multirow[t]{2}{*}{$p$-Value ${ }^{a}$} \\
\hline & $\mathrm{N}=1577(\%)$ & N (\%) & N (\%) & \\
\hline Gender & & & & 0.359 \\
\hline Male & $617(39.1 \%)$ & $577(93.5 \%)$ & $40(6.5 \%)$ & \\
\hline Female & $960(60.9 \%)$ & $886(92.3 \%)$ & $74(7.7 \%)$ & \\
\hline Age group & & & & $<0.01$ \\
\hline$<40$ & $288(18.3 \%)$ & $239(82.9 \%)$ & $49(17.1 \%)$ & \\
\hline $40-70$ & $776(49.2 \%)$ & $740(95.4 \%)$ & $36(4.6 \%)$ & \\
\hline$\geq 70$ & $513(32.7 \%)$ & $484(94.3 \%)$ & $29(5.7 \%)$ & \\
\hline BMI group & & & & $<0.01$ \\
\hline Underweight $(<18.5)$ & $159(10.1 \%)$ & $116(73.0 \%)$ & $43(27.0 \%)$ & \\
\hline
\end{tabular}


Table 2. Cont.

\begin{tabular}{ccccc}
\hline & $\begin{array}{c}\text { Number of } \\
\text { Patients }\end{array}$ & $\begin{array}{c}\text { MRSA (-) } \\
(\mathbf{1 4 6 3} \text { Patients) }\end{array}$ & $\begin{array}{c}\text { MRSA (+) } \\
(\mathbf{1 1 4} \text { Patients) }\end{array}$ & \multirow{2}{*}{$\boldsymbol{p}$-Value a } \\
\cline { 2 - 4 } & $\mathbf{N}=\mathbf{1 5 7 7}(\mathbf{\%})$ & $\mathbf{N ~ ( \% )}$ & $\mathbf{N ~ ( \% )}$ & \\
\hline Normal (18.5-25) & $735(46.6 \%)$ & $686(93.3 \%)$ & $49(6.7 \%)$ & \\
Overweight (25-30) & $566(35.9 \%)$ & $549(97.0 \%)$ & $17(3.0 \%)$ & \\
Obese ( $\geq 30)$ & $117(7.4 \%)$ & $112(95.7 \%)$ & $5(4.3 \%)$ & $<0.01$ \\
\hline Smoking & & & & \\
Never-smoker & $1294(82.1 \%)$ & $1226(94.7 \%)$ & $68(5.3 \%)$ & $<0.01$ \\
Current-smoker & $238(15.1 \%)$ & $193(81.1 \%)$ & $45(18.9 \%)$ & \\
Ex-smoker & $45(2.9 \%)$ & $44(97.8 \%)$ & $1(2.2 \%)$ & \\
Alcohol & & & & \\
Never-drinker & $1292(81.9 \%)$ & $1228(95.0 \%)$ & $64(5.0 \%)$ & \\
Current-drinker & $248(15.7 \%)$ & $198(79.8 \%)$ & $50(20.2 \%)$ & \\
Former-drinker & $37(2.3 \%)$ & $37(100.0 \%)$ & $0(0.0 \%)$ & \\
\hline Status of education & & & & \\
Under high school & $89(5.6 \%)$ & $82(92.1 \%)$ & $7(7.9 \%)$ & \\
High school graduate & $420(26.6 \%)$ & $374(89.0 \%)$ & $46(11.0 \%)$ & \\
Denied, Unanswered & $1068(67.7 \%)$ & $1007(94.3 \%)$ & $61(5.7 \%)$ & \\
\hline
\end{tabular}

$\mathrm{x} \%=$ = Column percentage; $\mathrm{N}(\mathrm{x} \%)$ = Number of patients (row percentage). OR = Odds ratio; $\mathrm{CI}=$ Confidence Interval; $\mathrm{a}=$ chi-square test. MRSA = Methicillin-resistant Staphylococcus aureus.

Table 3. Descriptive logistic regression analysis from data obtained at admission (medical comorbidities, other risk factors for MRSA).

\begin{tabular}{|c|c|c|c|c|}
\hline & $\begin{array}{c}\text { Number of } \\
\text { Patients }\end{array}$ & $\begin{array}{c}\text { MRSA (-) } \\
\text { (1463 Patient) }\end{array}$ & $\begin{array}{c}\text { MRSA (+) } \\
\text { (114 Patient) }\end{array}$ & \multirow[t]{2}{*}{$p$-Value ${ }^{a}$} \\
\hline & $\mathrm{N}=1577(\%)$ & N (\%) & $\mathbf{N}(\%)$ & \\
\hline Hypertension & & & & 0.059 \\
\hline No & $919(58.3 \%)$ & $843(91.7 \%)$ & $76(8.3 \%)$ & \\
\hline Yes & $658(41.7 \%)$ & $620(94.2 \%)$ & $38(5.8 \%)$ & \\
\hline $\begin{array}{c}\text { Cardiovascular } \\
\text { disease }\end{array}$ & & & & 0.510 \\
\hline $\mathrm{No}$ & $1486(94.2 \%)$ & 1377 (92.7\%) & $109(7.3 \%)$ & \\
\hline Yes & $91(5.8 \%)$ & $86(94.5 \%)$ & $5(5.5 \%)$ & \\
\hline Diabetes Mellitus & & & & 0.697 \\
\hline No & $1236(78.4 \%)$ & $1145(92.6 \%)$ & $91(7.4 \%)$ & \\
\hline Yes & $341(21.6 \%)$ & $318(93.3 \%)$ & $23(6.7 \%)$ & \\
\hline Hepatic disease & & & & 0.516 \\
\hline No & $1502(95.2 \%)$ & $1392(92.7 \%)$ & $110(7.3 \%)$ & \\
\hline Yes & $75(4.8 \%)$ & $71(94.7 \%)$ & $4(5.3 \%)$ & \\
\hline Dialysis & & & & $0.405^{*}$ \\
\hline No & $1565(99.2 \%)$ & $1451(92.7 \%)$ & $114(7.3 \%)$ & \\
\hline Yes & $12(0.8 \%)$ & $12(100.0 \%)$ & $0(0.0 \%)$ & \\
\hline $\begin{array}{c}\text { Recent } \\
\text { hospitalization }\end{array}$ & & & & 0.951 \\
\hline No & $1172(74.3 \%)$ & 1087 (92.7\%) & $85(7.3 \%)$ & \\
\hline Yes & $405(25.7 \%)$ & $376(92.8 \%)$ & $29(7.2 \%)$ & \\
\hline Recent antibiotics & & & & $<0.01$ \\
\hline No & $1105(70.1 \%)$ & $1061(96.0 \%)$ & $44(4.0 \%)$ & \\
\hline Yes & $472(29.9 \%)$ & $402(85.2 \%)$ & $70(14.8 \%)$ & \\
\hline
\end{tabular}


Table 3. Cont.

\begin{tabular}{ccccc}
\hline & $\begin{array}{c}\text { Number of } \\
\text { Patients }\end{array}$ & $\begin{array}{c}\text { MRSA (-) } \\
(\mathbf{1 4 6 3} \text { Patient) }\end{array}$ & $\begin{array}{c}\text { MRSA (+) } \\
(\mathbf{1 1 4} \text { Patient) }\end{array}$ & \multirow{2}{*}{$\boldsymbol{p}$-Value } \\
\cline { 2 - 4 } & $\mathbf{N}=\mathbf{1 5 7 7}(\mathbf{\%})$ & $\mathbf{N ~ ( \% )}$ & $\mathbf{N ~ ( \% )}$ & \\
\hline Urinary catheter & & & & 0.985 \\
No & $1329(84.3 \%)$ & $1233(92.8 \%)$ & $96(7.2 \%)$ & \\
Yes & $248(15.7 \%)$ & $230(92.7 \%)$ & $18(7.3 \%)$ & \\
\hline Route of admission & & & & $<0.01$ \\
ER & $227(14.4 \%)$ & $174(76.7 \%)$ & $53(23.3 \%)$ & \\
OPD & $1350(85.6 \%)$ & $1289(95.5 \%)$ & $61(4.5 \%)$ & \\
Body part involved & & & & \\
Spine & $567(36.0 \%)$ & $543(95.8 \%)$ & $24(4.2 \%)$ & \\
Knee, shoulder & $531(33.7 \%)$ & $506(95.3 \%)$ & $25(4.7 \%)$ & \\
Hand, elbow & $64(4.1 \%)$ & $64(100.0 \%)$ & $0(0.0 \%)$ & \\
Hip & $127(8.1 \%)$ & $119(93.7 \%)$ & $8(6.3 \%)$ & \\
Foot & $288(18.1 \%)$ & $231(80.2 \%)$ & $57(19.8 \%)$ & \\
Disease/Trauma & & & & \\
Trauma & $560(35.5 \%)$ & $500(89.3 \%)$ & $60(10.7 \%)$ & \\
Disease & $1017(64.5 \%)$ & $963(94.7 \%)$ & $54(5.3 \%)$ & \\
\hline
\end{tabular}

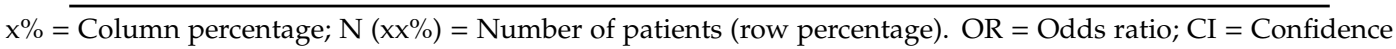
Interval. $\mathrm{a}=$ chi-square test or ${ }^{*}$ Fisher's exact test.

Table 4. Univariable and multivariable logistic regression analysis of the risk factors associated with MRSA colonization.

\begin{tabular}{|c|c|c|c|c|}
\hline Variables & $\begin{array}{c}\text { Univariable Analysis } \\
\text { OR }(95 \% \text { CI })\end{array}$ & $p$-Value & $\begin{array}{l}\text { Multivariable Analysis } \\
\text { Adjusted OR }(95 \% \text { CI) }\end{array}$ & $p$-Value \\
\hline \multicolumn{5}{|l|}{ Age } \\
\hline$<40$ & 1 & & & \\
\hline $40-70$ & $0.237(0.151-0.374)$ & $<0.01 * *$ & & \\
\hline$>70$ & $0.292(0.180-0.474)$ & $<0.01 * *$ & & \\
\hline \multicolumn{5}{|l|}{ BMI } \\
\hline Normal weight & 1 & & 1 & \\
\hline Underweight & $3.432(1.308-9.000)$ & $0.012 * *$ & $2.026(1.115-3.680)$ & $0.020^{* *}$ \\
\hline Overweight & $0.290(0.153-0.550)$ & $<0.01 * *$ & $0.389(0.219-0.689)$ & $<0.01 * *$ \\
\hline Obese & $0.637(0.238-1.702)$ & 0.369 & $0.637(0.246-1.650)$ & 0.354 \\
\hline \multicolumn{5}{|l|}{ Smoking } \\
\hline Never-smoker & 1 & & & \\
\hline Current-smoker & $4.204(2.801-6.309)$ & $<0.01 * *$ & & \\
\hline Ex-smoker & $0.410(0.056-3.019)$ & 0.381 & & \\
\hline \multicolumn{5}{|l|}{ Alcohol } \\
\hline Never-drinker & 1 & & & \\
\hline Current-drinker & $4.204(3.250-7.223)$ & $<0.01 * *$ & & \\
\hline Former-drinker & N/A & & & \\
\hline Hypertension & $0.680(0.454-1.017)$ & 0.061 & & \\
\hline \multicolumn{5}{|l|}{ Code } \\
\hline Disease & 1 & & 1 & \\
\hline Trauma & 3.401 (1.593-7.261) & $<0.01 * *$ & $1.795(0.984-3.275)$ & $0.048^{* *}$ \\
\hline Recent antibiotics use & $4.119(2.831-6.228)$ & $<0.01 * *$ & $1.946(1.178-3.217)$ & $<0.01 * *$ \\
\hline \multicolumn{5}{|l|}{ Route of admission } \\
\hline OPD & 1 & & 1 & \\
\hline ER & 6.915 (2.863-16.702) & $<0.01 * *$ & $3.998(2.003-7.979)$ & $0.047 * *$ \\
\hline
\end{tabular}




\subsubsection{Multiple Logistic Regression Analysis}

Table 4 shows the results of the multiple logistic regression analysis for the risk factors found statistically significant in the univariate logistic regression analysis. Being underweight, having trauma, recent antibiotic use, and admission through the emergency room were found to be risk factors. Patients with a BMI lower than $18.5 \mathrm{~kg} / \mathrm{m}^{2}$ had a 2.026 times higher risk of nasal MRSA carriage than patients with normal BMI. Patients diagnosed with trauma had a 1.795 times higher rate of nasal MRSA carriage than those diagnosed with disease. In addition, patients with recent antibiotics use had a 1.946 times higher risk of MRSA carriage than patients without antibiotic use. Furthermore, patients admitted through the emergency department had a 3.998 times higher MRSA carriage rate than those admitted through the outpatient department.

\section{Discussion}

According to this study, the overall prevalence of nasal MRSA carriage is $7.2 \%$. There is a huge difference in the epidemiology of MRSA worldwide. For example, the prevalence of community-associated MRSA infection in Japan, Germany, Turkey, Taiwan, and Malta was found to be $0.94 \%$ [29], $1.2 \%$ [17], 1.2\% [30], 3.8\% [31], and 8.81\% [6] respectively. These differences can be attributed to variations in microbiological methods (sampling technique, culture sites, and method of MRSA identification), local infection control standards, and the local prevalence of MRSA. Gi et al. [32] reported that the methicillin resistance rate of staphylococcal isolates in Korea is slightly higher than that in other countries. Another study showed that the prevalence of MRSA is $73 \%$ among the nosocomial S. aureus isolates in Korea, which is higher than that in other Asian countries [21]. Therefore, we considered it worthwhile to study the prevalence and risk factors for MRSA colonization in the orthopedic field, where aseptic surgery is essential.

Several studies have evaluated the risk factors associated with MRSA carriage [33-38]. Of the many known risk factors, the present study identified being underweight, having a diagnosis of trauma, recent antibiotic use, and admission through the emergency department as significant risk factors for MRSA carriage. Contrary to some prior studies, the present study did not reveal age as a significant risk factor $[35,36]$. The majority of studies have reported that the elderly patients have a higher tendency of being an MRSA carrier. An increased burden of infection in the elderly is linked to age-related decline in immune function, malnutrition, and anatomical and physiological changes [35]. However, some studies have reported that MRSA colonization is not influenced by age [39], and others found a higher carriage rate in younger patients [36]. Therefore, the association between age and MRSA colonization remains controversial.

Our results showed that being underweight is a risk factor for MRSA colonization and being overweight decreases the colonization rate. However, obesity did not turn out to be a significant risk factor for MRSA colonization in this study. Neidhart et al. [17] reported a reduced risk for S. aureus carriage in obese (BMI $\geq 30.0 \mathrm{~kg} / \mathrm{m}^{2}$ ) compared to overweight patients (BMI of 25.0 to $30 \mathrm{~kg} / \mathrm{m}^{2}$ ). However, other studies reported the opposite result. Olsen et al. [40] found a significant positive correlation between BMI and MRSA carriage only in women, particularly among those aged 30-43 years. Campbell et al. [41] reported an increased risk of $S$. aureus colonization in patients with both obesity and asthma. The analysis of skin and soft tissue staphylococcal infections showed that obesity is related to the presence of methicillin resistance. Therefore, further studies are needed to prove a definite relation between BMI and MRSA colonization.

In this study, smoking was not found to be a statistically significant risk factor for MRSA carriage. The influence of smoking on the colonization of MRSA is still controversial. Some studies proposed that smokers have higher rates of MRSA colonization than nonsmokers, thus increasing their risk of serious and difficult-to-treat infections [42,43]. Ellisa et al. reported that cigarette smoke increases MRSA hydrophobicity, thus increasing MRSA adherence and invasion [43]. They also stated that cigarette smoking increases the MRSA expression of genes linked to cell surface changes. In contrast, the smoke itself seems to influence the $S$. aureus load as indicated by the reduced identification rate 
in the upper respiratory tract [44]. A possible explanation for this finding is the inherent toxicity of smoke. The capability of smoke to inhibit the growth capacity of Gram-positive bacteria, particularly S. aureus, has already been demonstrated [45]. However, whether smoking affects MRSA colonization remains unclear.

In our study, patients admitted through the emergency department and those diagnosed with trauma had 3.998 and 1.795 times higher risk of MRSA colonization, respectively. Most trauma patients tend to visit the emergency department, and these two factors were considered by us to be similar. Quach et al. [46] reported that a visit to the emergency department is associated with more than threefold increased risk of acute infection. Patients with morbid conditions are more likely to visit the emergency department than patients with less morbid conditions. In addition, admission through the emergency department may increase the chance of contact with these patients, which may be expected to increase the risk of acquiring an infection. Also, patterns of injury differ between different mechanisms of trauma [47] which may cause patients diagnosed with trauma to be more susceptible to MRSA. For example, certain mechanisms of trauma may result in skin injuries, which may serve as a portal for entry. Furthermore, overcrowding of the emergency department creates more opportunities for cross-transmission [48], and overworked medical staff may not follow preventive procedures and take inadequate precautions $[49,50]$. Our findings on the correlation between trauma, admission through the emergency department, and MRSA detection may be due to these factors.

This study proves the relationship between antibiotic use prior to admission and MRSA colonization. Muller et al. [28] reported individual exposure to fluoroquinolones and collective exposure to penicillin to be associated with MRSA isolation after adjustment for colonization pressure and other potential confounders. Tacconelli et al. [51] performed a meta-analysis of over 76 studies included 24,230 patients and found that the development of MRSA is significantly related to the length of antibiotic exposure. According to the Society for Healthcare Epidemiology of America guidelines for preventing nosocomial transmission of MRSA and vancomycin-resistant enterococci, the use of antimicrobial agents in US hospitals is commonly excessive or unnecessary [9]. This widespread use of antibiotics may create conditions in which resistant bacteria experience a competitive advantage.

There are some limitations to our study. First, only nasal swabs were performed by us as the screening test considering cost- and time-effectiveness. Some studies suggest that collecting samples from additional sites (throat, groin, and thorax) may contribute to a higher detection rate than using a single site [17]. The prevalence of MRSA colonization might have been higher if samples from additional sites were collected. However, the anterior nasal cavity is known to be the most common carrier site of MRSA [11,12]. Second, we focused mainly on the screening test but whether the result of the screening test actually contributed to the development of post-operative infection has not been investigated. Third, this is a single-institute and single-department study. Additional multi-center studies must be performed to determine the actual frequency and risk factors for MRSA in Korea.

However, the current study is valuable in that it is among the first to focus on the prevalence and risk factors for MRSA in the orthopedic patients in Korea. The importance of the nasal MRSA screening test will be further validated by analyzing the clinical outcomes of the patients with a positive swab.

\section{Conclusions}

The present study focused on the prevalence of MRSA colonization and associated risk factors among patients admitted to the orthopedic surgery department. Being underweight, having a trauma diagnosis, antibiotic use one month prior to admission, and admission through the emergency department are risk factors for MRSA infection. The relatively high prevalence of MRSA in this study highlights the importance of pre-operative screening tests for patients scheduled for surgery involving implant insertion, particularly those at risk for MRSA. Among high risk patients, elective surgery could be delayed until the confirmation of the MRSA screening test. Prophylactic treatment prior to surgery is recommended for patients with positive MRSA colonization. 
Author Contributions: Conceptualization, S.-W.C.; methodology, S.-W.C.; validation, S.-W.C.; formal analysis, J.K.; investigation, J.K. and S.-W.C.; resources, S.-W.C.; data curation, J.K. and S.P.; writing-original draft preparation, J.K.; writing—review and editing, J.C.L. and J.E.K. and M.J.B. and S.Y.P.; visualization, J.C.L.; supervision, B.-J.S.; funding acquisition, S.-W.C.

Funding: This study was supported by the Soonchunhyang University research foundation and National Research Foundation of Korea (NRF) grant funded by the Korea government (MIST). (2019R1A2B5B01005924).

Acknowledgments: The authors sincerely thank Soon-hyo Kwon and Jae Heon Kim for their assistance with patient data analysis and consolidation.

Conflicts of Interest: The authors declare no conflict of interest. The funders had no role in the design of the study; in the collection, analyses, or interpretation of data; in the writing of the manuscript, or in the decision to publish the results

\section{References}

1. Su, C.-H.; Chang, S.-C.; Yan, J.-J.; Tseng, S.-H.; Chien, L.-J.; Fang, C.-T. Excess Mortality and Long-Term Disability from Healthcare-Associated Staphylococcus aureus Infections: A Population-Based Matched Cohort Study. PLoS ONE 2013, 8, e71055. [CrossRef] [PubMed]

2. Parker, M.T.; Hewitt, J.H. Methicillin Resistance in Staphylococcus Aureus. Lancet 1970, $295,800-804$. [CrossRef]

3. Lee, J.C.; Baek, M.J.; Choi, S.W.; Kwon, S.H.; Kim, K.H.; Park, S.Y.; Kim, T.H.; Park, S.; Jang, H.D.; Chun, D.I.; et al. Retrospective analysis of culture-negative versus culture-positive postoperative spinal infections. Medicine (Baltimore) 2018, 97, e10643. [CrossRef] [PubMed]

4. Vettivel, J.; Bortz, C.; Passias, P.G.; Baker, J.F. Pyogenic Vertebral Column Osteomyelitis in Adults: Analysis of Risk Factors for 30-Day and 1-Year Mortality in a Single Center Cohort Study. Asian Spine J. 2019. [CrossRef] [PubMed]

5. Kim, J.H.; Ahn, D.K.; Kim, J.W.; Kim, G.W. Particular Features of Surgical Site Infection in Posterior Lumbar Interbody Fusion. Clin. Orthop. Surg. 2015, 7, 337-343. [CrossRef]

6. Scerri, J.; Monecke, S.; Borg, M.A. Prevalence and characteristics of community carriage of methicillin-resistant Staphylococcus aureus in Malta. J. Epidemiol. Glob. Health 2013, 3, 165-173. [CrossRef]

7. Roche, S.J.; Fitzgerald, D.; O’Rourke, A.; McCabe, J.P. Methicillin-resistant Staphylococcus aureus in an Irish orthopaedic centre: A five-year analysis. J. Bone Joint Surg. Br. 2006, 88, 807-811. [CrossRef] [PubMed]

8. Calfee, D.P.; Salgado, C.D.; Milstone, A.M.; Harris, A.D.; Kuhar, D.T.; Moody, J.; Aureden, K.; Huang, S.S.; Maragakis, L.L.; Yokoe, D.S. Strategies to Prevent Methicillin-Resistant Staphylococcus aureus Transmission and Infection in Acute Care Hospitals: 2014 Update. Infect. Control Hosp. Epidemiol. 2014, 35, S108-S132. [CrossRef]

9. Muto, C.A.; Jernigan, J.A.; Ostrowsky, B.E.; Richet, H.M.; Jarvis, W.R.; Boyce, J.M.; Farr, B.M. SHEA guideline for preventing nosocomial transmission of multidrug-resistant strains of Staphylococcus aureus and enterococcus. Infect. Control Hosp. Epidemiol. 2003, 24, 362-386. [CrossRef]

10. Infection Control Guidelines for Multidrug Resistant Microorganisms in Healthcare Facilities. Korea Center for Disease Control \& Prevention 2012. Available online: http://www.gidcc.or.kr/wp-content/uploads/2016/ 12/7/_3-\%EB\%8B\%A4\%EC\%A0\%9C\%EB\%82\%B4\%EC\%84\%B1\%EA\%B7\%A0/_\%EA\%B4\%80\%EB\%A6\% AC\%EC\%A7\%80\%EC\%B9\%A8.pdf (accessed on 14 April 2019).

11. Kluytmans, J.; van Belkum, A.; Verbrugh, H. Nasal carriage of Staphylococcus aureus: Epidemiology, underlying mechanisms, and associated risks. Clin. Microbiol. Rev. 1997, 10, 505-520. [CrossRef]

12. Lucet, J.C. The importance of detecting methicillin-resistant Staphylococcus aureus in an intensive care setting. Ann. Fr. Anesth. Reanim. 2002, 21, 384-391. [CrossRef]

13. Yano, K.; Minoda, Y.; Sakawa, A.; Kuwano, Y.; Kondo, K.; Fukushima, W.; Tada, K. Positive nasal culture of methicillin-resistant Staphylococcus aureus (MRSA) is a risk factor for surgical site infection in orthopedics. Acta Orthop. 2009, 80, 486-490. [CrossRef]

14. Nelwan, E.J.; Sinto, R.; Subekti, D.; Adiwinata, R.; Waslia, L.; Loho, T.; Safari, D.; Widodo, D. Screening of methicillin-resistant Staphylococcus aureus nasal colonization among elective surgery patients in referral hospital in Indonesia. BMC Res. Notes 2018, 11, 56. [CrossRef]

15. Price, C.S.; Williams, A.; Philips, G.; Dayton, M.; Smith, W.; Morgan, S. Staphylococcus aureus nasal colonization in preoperative orthopaedic outpatients. Clin. Orthop. Relat. Res. 2008, 466, 2842-2847. [CrossRef] [PubMed] 
16. Kim, D.H.; Spencer, M.; Davidson, S.M.; Li, L.; Shaw, J.D.; Gulczynski, D.; Hunter, D.J.; Martha, J.F.; Miley, G.B.; Parazin, S.J.; et al. Institutional prescreening for detection and eradication of methicillin-resistant Staphylococcus aureus in patients undergoing elective orthopaedic surgery. J. Bone Joint Surg. Am. 2010, 92, 1820-1826. [CrossRef]

17. Neidhart, S.; Zaatreh, S.; Klinder, A.; Redanz, S.; Spitzmuller, R.; Holtfreter, S.; Warnke, P.; Alozie, A.; Henck, V.; Gohler, A.; et al. Predictors of colonization with Staphylococcus species among patients scheduled for cardiac and orthopedic interventions at tertiary care hospitals in north-eastern Germany-A prevalence screening study. Eur. J. Clin. Microbiol. Infect. Dis. 2018, 37, 633-641. [CrossRef] [PubMed]

18. Kobayashi, K.; Ando, K.; Ito, K.; Tsushima, M.; Morozumi, M.; Tanaka, S.; Machino, M.; Ota, K.; Ishiguro, N.; Imagama, S. Prediction of surgical site infection in spine surgery from tests of nasal MRSA colonization and drain tip culture. Eur. J. Orthop. Surg. Traumatol. 2018, 28, 1053-1057. [CrossRef]

19. Song, J.-H.; Hsueh, P.-R.; Chung, D.R.; Ko, K.S.; Kang, C.-I.; Peck, K.R.; Yeom, J.-S.; Kim, S.-W.; Chang, H.-H.; Kim, Y.-S.; et al. Spread of methicillin-resistant Staphylococcus aureus between the community and the hospitals in Asian countries: An ANSORP study. J. Antimicrob. Chemother. 2011, 66, 1061-1069. [CrossRef]

20. Mendes, R.E.; Mendoza, M.; Singh, K.K.B.; Castanheira, M.; Bell, J.M.; Turnidge, J.D.; Lin, S.S.; Jones, R.N. Regional resistance surveillance program results for 12 Asia-Pacific nations (2011). Antimicrob. Agents Chemother. 2013, 57, 5721-5726. [CrossRef] [PubMed]

21. Chen, C.J.; Huang, Y.C. New epidemiology of Staphylococcus aureus infection in Asia. Clin. Microbiol. Infect. 2014, 20, 605-623. [CrossRef]

22. Shiwaku, K.; Anuurad, E.; Enkhmaa, B.; Kitajima, K.; Yamane, Y. Appropriate BMI for Asian populations. Lancet (London, England) 2004, 363, 1077. [CrossRef]

23. Ryan, H.; Trosclair, A.; Gfroerer, J. Adult current smoking: Differences in definitions and prevalence estimates-NHIS and NSDUH, 2008. J. Environ. Public Health 2012, 2012, 918368. [CrossRef] [PubMed]

24. Rostron, B. Alcohol Consumption and Mortality Risks in the USA. Alcohol Alcohol. 2012, 47, $334-339$. [CrossRef] [PubMed]

25. Bratu, S.; Landman, D.; Gupta, J.; Trehan, M.; Panwar, M.; Quale, J. A population-based study examining the emergence of community-associated methicillin-resistant Staphylococcus aureus USA300 in New York City. Ann. Clin. Microbiol. Antimicrob. 2006, 5, 29. [CrossRef]

26. Dufour, P.; Gillet, Y.; Bes, M.; Lina, G.; Vandenesch, F.; Floret, D.; Etienne, J.; Richet, H. Community-acquired methicillin-resistant Staphylococcus aureus infections in France: Emergence of a single clone that produces Panton-Valentine leukocidin. Clin. Infect. Dis. 2002, 35, 819-824. [CrossRef] [PubMed]

27. Bagger, J.P.; Zindrou, D.; Taylor, K.M. Postoperative infection with meticillin-resistant Staphylococcus aureus and socioeconomic background. Lancet 2004, 363, 706-708. [CrossRef]

28. Muller, A.; Mauny, F.; Talon, D.; Donnan, P.T.; Harbarth, S.; Bertrand, X. Effect of individual- and group-level antibiotic exposure on MRSA isolation: A multilevel analysis. J. Antimicrob. Chemother. 2006, 58, 878-881. [CrossRef]

29. Yamasaki, F.; Takeuchi, S.; Uehara, Y.; Matsushita, M.; Arise, K.; Morimoto, N.; Seo, H. Prevalence and characteristics of methicillin-resistant Staphylococcus aureus in community residents of Japan. J. Gen. Fam. Med. 2018, 19, 77-81. [CrossRef]

30. Oguzkaya-Artan, M.; Artan, C.; Baykan, Z. Prevalence and risk factors for Staphylococcus aureus and methicillin-resistant Staphylococcus aureus nasal carriage inpatients in a tertiary care hospital's chest clinic in Turkey. Niger. J. Clin. Pract. 2016, 19, 313-317. [CrossRef]

31. Lu, S.Y.; Chang, F.Y.; Cheng, C.C.; Lee, K.D.; Huang, Y.C. Methicillin-resistant Staphylococcus aureus nasal colonization among adult patients visiting emergency department in a medical center in Taiwan. PLoS ONE 2011, 6, e18620. [CrossRef]

32. Kang, G.S.; Jung, Y.H.; Kim, H.S.; Lee, Y.S.; Park, C.; Lee, K.J.; Cha, J.O. Prevalence of Major Methicillin-Resistant Staphylococcus aureus Clones in Korea Between 2001 and 2008. Ann. Lab. Med. 2016, 36, 536-541. [CrossRef]

33. Jernigan, J.A.; Pullen, A.L.; Flowers, L.; Bell, M.; Jarvis, W.R. Prevalence of and risk factors for colonization with methicillin-resistant Staphylococcus aureus at the time of hospital admission. Infect. Control Hosp. Epidemiol. 2003, 24, 409-414. [CrossRef] [PubMed] 
34. Lu, P.L.; Chin, L.C.; Peng, C.F.; Chiang, Y.H.; Chen, T.P.; Ma, L.; Siu, L.K. Risk factors and molecular analysis of community methicillin-resistant Staphylococcus aureus carriage. J. Clin. Microbiol. 2005, 43, 132-139. [CrossRef] [PubMed]

35. Sfeir, M.; Obeid, Y.; Eid, C.; Saliby, M.; Farra, A.; Farhat, H.; Mokhbat, J.E. Prevalence of Staphylococcus aureus methicillin-sensitive and methicillin-resistant nasal and pharyngeal colonization in outpatients in Lebanon. Am. J. Infect. Control 2014, 42, 160-163. [CrossRef] [PubMed]

36. Munckhof, W.J.; Nimmo, G.R.; Schooneveldt, J.M.; Schlebusch, S.; Stephens, A.J.; Williams, G.; Huygens, F.; Giffard, P. Nasal carriage of Staphylococcus aureus, including community-associated methicillin-resistant strains, in Queensland adults. Clin. Microbiol. Infect. 2009, 15, 149-155. [CrossRef] [PubMed]

37. Halablab, M.A.; Hijazi, S.M.; Fawzi, M.A.; Araj, G.F. Staphylococcus aureus nasal carriage rate and associated risk factors in individuals in the community. Epidemiol. Infect. 2010, 138, 702-706. [CrossRef]

38. Liang, Z.; Zhang, Q.; Thomas, C.M.; Chana, K.K.; Gibeon, D.; Barnes, P.J.; Chung, K.F.; Bhavsar, P.K.; Donnelly, L.E. Impaired macrophage phagocytosis of bacteria in severe asthma. Respir. Res. 2014, 15, 72. [CrossRef] [PubMed]

39. Khanal, R.; Sah, P.; Lamichhane, P.; Lamsal, A.; Upadhaya, S.; Pahwa, V.K. Nasal carriage of methicillin resistant Staphylococcus aureus among health care workers at a tertiary care hospital in Western Nepal. Antimicrob. Resist. Infect. Control 2015, 4, 39. [CrossRef]

40. Olsen, K.; Sangvik, M.; Simonsen, G.S.; Sollid, J.U.E.; Sundsfjord, A.; Thune, I.; Furberg, A. Prevalence and population structure of Staphylococcus aureus nasal carriage in healthcare workers in a general population. The Tromsø Staph and Skin Study. Epidemiol. Infect. 2013, 141, 143-152. [CrossRef]

41. Campbell, K.A.; Cunningham, C.; Hasan, S.; Hutzler, L.; Bosco, J.A., 3rd. Risk Factors for Developing Staphylococcus aureus Nasal Colonization in Spine and Arthroplasty Surgery. Bull. Hosp. Jt. Dis. (2013) 2015, 73, 276-281.

42. Durmaz, R.; Tekerekoglu, M.S.; Kalcioglu, T.; Ozturan, O. Nasal carriage of methicillin-resistant Staphylococcus aureus among smokers and cigarette factory workers. New Microbiol. 2001, 24, 143-147. [PubMed]

43. McEachern, E.K.; Hwang, J.H.; Sladewski, K.M.; Nicatia, S.; Dewitz, C.; Mathew, D.P.; Nizet, V.; Crotty Alexander, L.E. Analysis of the Effects of Cigarette Smoke on Staphylococcal Virulence Phenotypes. Infect. Immun. 2015, 83, 2443-2452. [CrossRef] [PubMed]

44. Qu, F.; Cui, E.; Guo, T.; Li, H.; Chen, S.; Liu, L.; Han, W.; Bao, C.; Mao, Y.; Tang, Y.W. Nasal colonization of and clonal transmission of methicillin-susceptible Staphylococcus aureus among Chinese military volunteers. J. Clin. Microbiol. 2010, 48, 64-69. [CrossRef] [PubMed]

45. Ertel, A.; Eng, R.; Smith, S.M. The differential effect of cigarette smoke on the growth of bacteria found in humans. Chest 1991, 100, 628-630. [CrossRef]

46. Quach, C.; McArthur, M.; McGeer, A.; Li, L.; Simor, A.; Dionne, M.; Lévesque, E.; Tremblay, L. Risk of infection following a visit to the emergency department: A cohort study. CMAJ 2012, 184, E232-E239. [CrossRef]

47. Cameron, P.; Dziukas, L.; Hadj, A.; Clark, P.; Hooper, S. Patterns of injury from major trauma in Victoria. Aust. N. Z. J. Surg. 1995, 65, 848-852. [CrossRef]

48. Clements, A.; Halton, K.; Graves, N.; Pettitt, A.; Morton, A.; Looke, D.; Whitby, M. Overcrowding and understaffing in modern health-care systems: Key determinants in meticillin-resistant Staphylococcus aureus transmission. Lancet Infect. Dis. 2008, 8, 427-434. [CrossRef]

49. Chen, Y.-C.; Huang, L.-M.; Chan, C.-C.; Su, C.-P.; Chang, S.-C.; Chang, Y.-Y.; Chen, M.-L.; Hung, C.-C.; Chen, W.-J.; Lin, F.-Y.; et al. SARS in hospital emergency room. Emerg. Infect. Dis. 2004, 10, 782-788. [CrossRef]

50. Messina, G.; Rosadini, D.; Burgassi, S.; Messina, D.; Nante, N.; Tani, M.; Cevenini, G. Tanning the bugs-A pilot study of an innovative approach to stethoscope disinfection. J. Hosp. Infect. 2017, 95, 228-230. [CrossRef]

51. Tacconelli, E.; De Angelis, G.; Cataldo, M.A.; Pozzi, E.; Cauda, R. Does antibiotic exposure increase the risk of methicillin-resistant Staphylococcus aureus (MRSA) isolation? A systematic review and meta-analysis. J. Antimicrob. Chemother. 2008, 61, 26-38. [CrossRef]

(C) 2019 by the authors. Licensee MDPI, Basel, Switzerland. This article is an open access article distributed under the terms and conditions of the Creative Commons Attribution (CC BY) license (http://creativecommons.org/licenses/by/4.0/). 